\title{
An Overview Of The Lexical Approach And Its Implementation At A Public Elementary School In South Korea
}

\author{
Mark Graham Sample, Hankuk University of Foreign Studies, South Korea
}

\begin{abstract}
Michael Lewis' Lexical Approach attempted to turn the EFL world on its head by proposing that language acquisition comes from lexis rather than grammar. Lewis states that "language consists not of traditional grammar and vocabulary but often of multi-word prefabricated chunks" (1997:3). Lewis' 1997 handbook, 'Implementing the Lexical Approach', encourages teachers to focus students' attention towards chunks of language by altering a large number of their classroom procedures. This paper outlines traditional views towards language learning before observing the principles and criticisms of the Lexical Approach. Finally, it details the author's teaching context at a public elementary school and the experiences he had whilst implementing a weak version of the approach teaching eight to ten-year-old students.
\end{abstract}

Keywords: Lexical Approach; Lexis; Prefabricated Chunk; Grammaticalized Lexis

\section{INTRODUCTION}

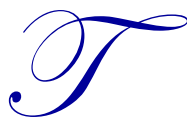

he focus of this paper is Michael Lewis' Lexical Approach (LA) which since its publication in 1993 has continued to provoke wide debate. Lewis' ideas advance on The Lexical Syllabus (1990) and the Collins COBUILD English Course (1989). Richards and Rodgers explain that LA is "derived from the belief that the building blocks of language learning and communication are not grammar, functions, notions, or some other unit of planning and teaching but lexis, that is, words and word combinations" (2001:132).

This paper will firstly explore some of the traditional approaches to the teaching of grammar and vocabulary. Secondly, it will outline the principles of Michael Lewis' Lexical Approach and then observe some of its criticisms. Next, the author will summarize his teaching context at a public elementary school in Seoul, South Korea in 2012. Finally, the author will note his observations when he incorporated a weak version of Lewis' approach into his classroom procedures with students aged eight to ten-years-old.

\section{Traditional Approaches}

The traditional view was that language is atomistic with grammar as the 'structure' of language and vocabulary as the 'words' that fit into the structure. A syllabus writer from the sixties reflects the opinion of traditional approaches that cited the emphasis on grammar learning by stating that; "one of the basic aims is to enable the student to use a number of high-frequency patterns rather than to build up a large vocabulary" (Alexander 1967: xviii).

One of the oldest concepts, the 'Grammar Translation Method' which dominated from the 1840s-1940s carried the view that a foreign language was only required in order to read or write and thus little or no attention was paid to speaking and listening. Stern states that "the first language is maintained as the reference system in the acquisition of the second language" (1983:445), which meant that the language was taught in language 1 (L1). Richards and Rodgers explain that a typical lesson would be spent translating sentences with the "tedious experience 
of memorizing endless lists of unusable grammar rules and vocabulary" (2001:6). This method felt the weight of criticism the more people began to travel among other countries and desired the ability to communicate vocally.

The early $20^{\text {th }}$ century saw the Direct Method rise to fame as the answer to providing communicative language learning. Its main principles were classroom instruction in language 2 (L2), the teaching of everyday sentences and vocabulary, grammar taught inductively, and the focus on correct pronunciation and grammar. These were two early methods, but since the 1950s there have been a vast number of concepts which have flooded the industry.

At about the same time Situational Language Teaching came to prominence in Europe, the Audiolingual Method took precedence in America. Both held similar principles, regarding language as a set of structures, focusing on oral teaching through L2 and the careful selection of essential vocabulary. The objective was to teach students spoken language that could be used in real life situations. Nevertheless grammar was still the basis and it was graded on the logic that simple terms should be taught before complex terms. Also, reading and writing were only introduced once students had sufficient lexical and grammatical knowledge.

Richards and Rogers explain that the 1970's and 1980's saw a big change with the birth of humanistic ideas and "the quest for alternatives to grammar based approaches and methods led in several different directions" (2001:71). This paper will focus on the ideas of the communicative movement, which began to give the role of lexis a major rethink with regards to its meaning-making potential. Thornbury explains that "vocabulary, which had previously been seen as little more than a resource for filling in slots in grammatical structures, became a learning objective in its own right" (1998:7).

The birth of the Communicative Language Teaching (CLT) came with the Functional Notional Syllabus. Rather than being organized by grammatical structure, language was arranged through notions and functions, something which had happened previously, but only now was it taking priority. White defines "firstly a notional or conceptual aspect, which is concerned with such concepts as time, space, movement, cause and effect; and secondly, a functional aspect, with which the intentional or purposive use of language is described and classified" (1998:74). For instance the 'notion' of shopping requires language 'functions' such as asking about the price, the product or bargaining for example. The target was to teach everyday language through listening and reading first, and then later speaking activities would be introduced. Richard and Rodgers explain the overall aim was to make "communicative competence the goal of language teaching and (to) develop procedures for the teaching of the four language skills" (2001:155).

The early 1980's saw the next developments in CLT with the main principles being the division of classroom activities based on 'fluency' and 'accuracy'. Lowe explains that "accuracy work was for concentrating on learning new bits of language; fluency was for getting the students to speak freely" (2003:7). For example, in the accuracy part of the lesson students learned grammatical patterns, functional exponents or vocabulary, and then during the fluency part of the class they practiced speaking often through conversation or debate.

Task-Based Language Teaching (TBLT) which came to fruition in the mid 1980s is the last key development in CLT that the author will note. Feez (1998) highlights some of TBLT's key features; for instance, it was a process rather than a product, the activities focused on communication and meaning, and the tasks were graded in difficulty (1998:17). Additionally, it advocated the position of vocabulary playing a more central role in learning. For example, rather than being taught language points, students would be expected to complete communicative tasks by asking the teacher for the language parts they required to finish a task. The overall goal was to practice authentic language use through tasks, which would assist in the development of grammatical and lexical knowledge.

In this section, the author has outlined some of the key developments that have taken place in language teaching practices over time, and decisively, the notable rise in the importance of vocabulary teaching the closer we get to modern day strategies and techniques. This leads us to the LA which will be outlined in the following section. 


\section{Principles of Lewis' Lexical Approach}

The main item that distinguishes the LA from traditional approaches is its belief that language consists of grammaticalized lexis rather than lexicalized grammar. Lewis states that "grammar is not the basis of language acquisition, and the balance of linguistic research clearly invalidates any view to the contrary" (1993:133). Additionally, the approach ignores the belief that grammar and lexis are two separate segments and instead argues that language is made up of multi-word chunks.

Lewis explains that there are four basic types of chunk and these "when combined, produce continuous coherent text" (1997:7). The first category 'words' is the largest by far and contains language which reflects stand alone vocabulary like 'open' in a shop window, or words where a single substitution creates a whole new meaning such as 'salt' or 'pepper' in 'could you pass the ........... please?' (Lewis 1997:8). Additionally 'polywords', which are phrases that act like single words, reside in this category with 'by the way' an example. There is nothing groundbreaking in this category and it is in the next three categories that the main focus of the LA takes shape. The second category, 'collocations' explains how "certain words co-occur in natural text with greater than random theory" (Lewis 1997:8). A standard example of a collocation is 'white coffee', however, there are many forms which can be plotted on a strong to weak continuum. A strong example is 'auspicious', which will only collocate with a few words such as 'occasion, moment or event', whereas, a weak example like 'circuit' will collocate with numerous words such as 'short, closed or racing' to the left, and 'training or breaker' to the right. Lewis ties the final two categories, 'fixed expressions' and 'semi-fixed expressions', together despite accepting they can be distinguished. Fixed expressions such as 'surf the web' or 'fall in line' offer no variability. On the contrary, 'semifixed expressions' are far more common than fixed expressions and fall under a number of titles. Semi-fixed expressions can include certain idioms, can range from long to short, and nearly fully fixed to almost free. Examples include almost fully fixed expressions that offer some variation or slot sentences such as 'could you pass

please?' Frames found in formal letters or expressions like 'that's not ..... as you think' are other illustrations. Finally, idioms like 'it's the tip of the iceberg' may appear fixed but in practice they are often used as frames for novel expressions. Lewis believes expressions, both semi-fixed and fixed, are stored in our mental lexicon, and he suggests that our language is actually much less original than was initially thought. He states that "much of what we say, and a significant proportion of what we write, consists of pre-fabricated multi-word items" (1997:11). As this section has shown LA encourages primary focus towards vocabulary, and the learning of sentences or phrases that are most frequent in communication.

Proponents of the LA base their argument on the opinion that vocabulary holds more meaning than grammar. For example John Sinclair at the IATEFL in 1996 stated that "a lexical mistake often causes misunderstanding; while a grammar mistake rarely does" (cited Lewis 1997:16). Furthermore, Lewis sees lexis as the key to 'communicative power' and the fundamental reason why he places grammar in a subsidiary role. Lewis believes all language is arbitrary and uses the famous teaching cliché 'you could say that, but you wouldn't' as a slogan for the LA. He believes students should be taught the skills needed to chunk relevant language together to create what CLT calls 'communicative competence'. Rather than looking at the theoretical reasons for using particular language he believes language comes from what is chosen as the agreed way to say or write something. He uses the examples of "Happy Christmas, Happy Birthday, Merry Christmas and Merry Birthday" (1997:18). Even though Merry Birthday is grammatically correct we choose not to use it, so it has become unnatural English and considered incorrect. Lewis believes students need not be told the explanation of this, as it merely causes confusion and it should just be accepted that this is just the way language works. Furthermore, he suggests that what students ought to focus on is learning the "many pre-fabricated, but arbitrary chunks" (1997:20) that make up language. Additionally, the multi-word chunks that are taught should come from probable uses of English rather than possible uses of English, as this is the language learners are most likely to come into contact with outside of the classroom.

Lewis discredits the CLT technique of 'Presentation, Practice and Production' (PPP) stating that "the fact is the PPP paradigm is, and always was nonsense" (1996:11). Lewis believes it focuses too much on language patterns and it takes too long to master. Instead he offers an 'Observe, Hypothesize and Experiment' cycle that relates heavily to Krashen's Monitor Theory (1985) and calls for high quantities of input. Ignoring the traditional atomistic views to language, Krashen and Lewis believe language is holistic meaning lexis should be learned without analysis. 
Lewis promotes engaging learners in activities that provide large quantities of input in the form of listening exercises at beginner levels, and listening and reading exercises at higher levels. Lewis states that "students learn best in language rich classrooms and with language rich materials. Teachers must be unafraid of exposing their students to real English, at all stages...Listening, listening and more listening is necessary" (1993:193).

It is important to note that even though Lewis promotes using L2 as much as possible in the classroom he does recommend the use of L1 for some translation. Also, in contrast to CLT, he suggests using the help of a dictionary and a lexical notebook. Finally, it should be added that even though Lewis prioritises lexis over grammar, he still realizes the importance of grammar by stating "the approach in no way denies the value of grammar" (1997:41).

In the next section the author will observe some of the criticisms of the Lexical Approach.

\section{Criticism of the Lexical Approach}

Firstly, Boers and Lindstromberg (2009) in their book about optimizing the lexical approach argue Lewis' belief that teaching time should be spent instructing learners how to learn chunks incidentally and autonomously is too hard and time consuming. They suggest pre-selecting the chunks in advance, which enables more time and focus to be spent on a particular chunk that occurs frequently. Boers and Lindstromberg believe the increased exposure to a particular chunk raises the potential for it to be remembered by the learner. With this is mind, they give more responsibility to the teacher than Lewis, who in their opinion, relies too heavily on student autonomy.

Next, Thornbury suggests Lewis takes us on "a journey without maps" (1998:11) as his theories and beliefs are inconsistent, unproven and offer no clear syllabus guidelines. Firstly, the LA is heavily based on Krashen's theory which advocates learning lexis without analysis, even though there is still no proof that learning leads to acquisition. Furthermore, Thornbury notes that Lewis explains that he doesn't favour a lexical, grammatical or task based syllabus which leaves syllabus designers unsure of which method he actually advocates. In defence of this, Lewis does state that "a central requirement of the Lexical Approach is that language material should be text and discourse, rather than sentence based" (1993:112). However, Thornbury is also critical of this by stating that the approach does not "specify how texts and discourses would be selected and organized" (1998:11). This ties into the argument by Boers and Lindstromberg (2009) that the approach is too autonomous. Lewis' (1997) book only chooses to show exercise examples rather the clear guidance regarding syllabus design and the language that should be taught. Additionally, he shows inconsistencies regarding how languages are learned, as he supports Krashen's high input theory that places acquisition over learning, however, he also advocates the need for students to consciously recognize chunks. Next, Thornbury highlights the dangers of learning chunks comparing it to phrasebook type learning. The issue here is that students can have all the chunks, but without syntactic knowledge, they will be context bound and unable to adapt to different situations. Finally, Thornbury points out that Lewis makes no reference to grading in his approach.

Lindstromberg highlights the impracticality of a strong version of the LA by stating that he does not think this promises "the requisite increase in the rate of vocabulary learning" as students are forced to learn "tons and tons more vocabulary" (2000:6) to become comprehensively communicatively competent. Therefore, due to class time restriction, students using this approach are forced to study long lists of vocabulary outside of the classroom, which requires high levels of motivation. Lindstromberg argues that rather than learning the meanings of very important single words such as prepositions, which are essential to sentence building, students are instead forced to memorize endless amounts of phrases with little understanding of their grammatical foundation.

More recently Lewis (2000) himself realized the limited basis in the learning theory the LA holds. He accepted the problems with making 'input' become 'intake' particularly with regard to lexical chunks or collocations and that the amount of input required is too much. 


\section{The Author's Teaching Context}

In 2012, as a teacher at a state run public elementary school in Seoul, South Korea, the author was tasked with instructing eight to ten-year-olds three times each a week for 40 minutes per class. Class sizes were relatively large with between 25-30 mixed-level students in each. Seog et al. states that "The education system in Korea is highly centralized, and the government maintains strict control over educational curricula, teacher training, budget and national entrance exams" (2011:91). With this in mind, the author's command over what was taught was somewhat restricted. However, in his circumstance there was some freedom with regards to the methods used to teach the material. Wollam (1992) who investigated Korean education found that individuals in South Korea have long associated their achievements on competitive examinations with success, status and prestige. Thus despite the students being young, most of the parents and students clearly emphasized that the overriding goal of their English classes was to ultimately score highly on the national exams. Therefore, as the exam was based on the textbook content, to meet students' needs, it was fundamental that the textbook took precedence when designing the curriculum.

The textbooks, English 3 (Sohn 2012) and English 4 (Sohn 2012), for the two each age groups the author taught (eight to nine-years-old and nine to ten-years-old), followed the exact same structure with difficulty and quantity increasing with time, and the intent on improving communicative competence. The two semester textbook was broken down into 16 chapters with four lessons spent on each chapter. Each chapter title reflected a mixture of a grammatical structure and a theme for the four lessons; for example 'let's play soccer' from a fourth grade text book. In this chapter the theme was hobbies and the grammatical elements covered, were suggestions and possible positive and negative responses. Throughout the four lessons the objective was to drill approximately 20 key vocabulary terms and for students to be able to use them in the sentence forms covered during that chapter. Revisiting above, it should be understood that everything was taught with the national exam in mind, however, in the author's case most students were at a higher level relative to their age. This was because the school was located in a rich neighbourhood and the vast majority of the students attended private English academies outside of school hours or/and had lived in an L2 country. The mixed level classes provided complications as the textbook was too easy for most, but the standard teaching method had to be followed to accommodate the minority of lower level students that occupied each class. To overcome this issue the author provided a variety of additional activities for the higher level students in the later lessons once they had covered all the material in the textbook. This enabled the author time to give extra attention to the lower level students. A general sixth grade 40 minute class was taught in L2 and incorporated reading, listening and speaking practice. At these two levels there was very little time spent on writing activities except for tracing new vocabulary words. Time restrictions meant that the classes were highly structured and the author had to maintain strict control over the time that was spent on each activity to ensure all the content was covered.

\section{Implementing LA into the Author's Context}

Due to the author's teaching context, it was impossible to implement a strong version of the LA. Nevertheless, the author incorporated some of Lewis' ideas into his teaching procedures which represented a weak version of the approach.

Firstly, the textbooks themselves actually encompassed elements of the LA. As the author mentioned in the section above, all of the textbooks followed the same pattern of introducing a new grammatical structure such as 'Let's ___. This is recognized by Lewis as a semi-fixed expression with a slot that can be filled with a number of words such as 'play soccer' or 'watch television'.

Secondly, the author littered the walls with frequent, semi and fixed, expressions within different categories that he saw useful to his students. For example under the title of 'Classroom English', two examples were, 'I don't understand' and 'May I go to ?' The author gave the students printed copies of these lists to take home with the instruction to memorize two expressions between each class. Although the author observed throughout the semester that they successfully memorized some of the more frequent and easier expressions, this was only a small proportion of the entire list. The majority of students would use the expression correctly during the first lesson after the homework was assigned, but would have difficulties reciting the entire expression in later classes during review 
and recycling activities. Often students would know part or even all of the expression, but they would mix-up the word order, or jumble words together words from a number of different expressions.

Additionally, like Lewis, the author promoted recycling and recording language to increase the likelihood of acquisition. All of the students kept a notebook of the language items covered in class and review activities were carried out frequently. This proved successful as the lists in their notebooks were linked to the textbook and the students were more motivated to study the vocabulary as it was likely to be on their examination. However, the author selected the content for the notebooks, which goes against the greater autonomy that Lewis promotes. He did this to satisfy the needs of his students who wanted to focus on the language that they were likely to face during their examination and to limit input somewhat as many evidently found it overwhelming. Furthermore, this reflects the recommendation of Boers and Lindstromberg (2009), which the author highlighted in the criticisms of the LA section. As an extension for the higher level students, the author made students create collocation boxes in their notebooks. The author would give them a noun and they would be tasked with finding verbs that collocate with it. An example used in the class is shown below:

\begin{tabular}{|l|c|}
\hline \multicolumn{1}{|c|}{ 5 verbs } & + noun \\
\hline 1. & \\
2. & friends \\
3. & \\
4. & \\
5. & \\
\hline
\end{tabular}

The other notebook related activity the author tasked his advanced students with was forming sentences using specific word partnerships. He would choose a key word and give each student a hand-out to stick in their notebook. The students then analysed the key word, items that frequently occur to the left or right of it and some concordance sentences. Next, they formed their own personal examples below the box by writing the target language in the slots. One example used is shown here:

\begin{tabular}{|l|l|l|}
\hline Keyword: Mess \\
\hline be & & $\begin{array}{l}\text { It was a pretty big mess. } \\
\text { My room is a terrible mess. } \\
\text { make }\end{array}$ \\
clean up & a (terrible / big / huge) mess & $\begin{array}{l}\text { We made a huge mess at school. } \\
\text { I need to clean up the mess on my desk. } \\
\text { Please clean up that terrible mess! }\end{array}$ \\
\hline
\end{tabular}

Student Examples:

a. is a mess.

b. I made mess when

c. I need to the mess in/on

A number of students reported that they preferred this format to the traditional long lists of vocabulary as it was clearer and easier to review because they could form a mental image of the boxes. However, the author did notice especially with the second activity that some students appeared overwhelmed by the increased input. This reinforced his decision to take control over the target language and reduce student autonomy, which may work better with older students.

Next, a more modern aspect that the author integrated into his lessons was the use of computerized corpora which has developed with time and greatly aided Lewis' approach. Early corpora such as COBUILD assisted in establishing what language students needed to learn, but in the early days examples like the Collins COBUILD English course were unsuccessful perhaps due to their radicalism. However, today developments have been made such as 'Touchstone', which has been specifically designed for students learning English. McCarthy explains how 
the authors of Touchstone spent several years researching the corpus to find the most useful grammar and vocabulary for learners uncovering how people communicate in everyday situations (2004:6). Teachers can explore the frequency of vocabulary or grammar terms to see what is most relevant to their students. Furthermore, Moudraia suggests teachers can produce concordances which show how a word is used in different contexts to "research word partnerships, preposition usage, style and so on" (2001:2). In the author's classes once a week, he used the large television with internet access to pull up hyperlinks with concordances of the vocabulary being studied in a particular lesson. However, although the author's students were initially interested in this new concept, they seemed to lose interest and motivation as the semester went on. This could be attributed to the age of his students and Lindstromberg observation that "concordance analysis is a highly bookwormy type of activity and few people are willing bookworms" (2000:5). The lists consisted of many sentences and this seemed to overwhelm the students. The results may have been better if the author had of preselected a limited number of sentences to focus on. Another activity the author introduced involved guessing new vocabulary terms by exploring the context of the word first. This proved successful when used in small quantities, however like above; the level of reading which involved a lot of new vocabulary often hindered the objective of focusing on a specific lexical item.

Finally, in certain lessons the author gave each student a basic dictionary and encouraged them to actively search words that they did not know when they came across them in class. This was to encourage more autonomous learning that Lewis advocates, however, it proved a distraction to many of the students and would most likely be better suited to older students.

\section{CONCLUSION}

This paper has outlined Lewis' LA, a number of its drawbacks, and also, the teaching context the author applied a weak version of the approach to. The author believes that the LA certainly offers practical ideas that can be incorporated into classroom procedures, but only alongside other methods as it certainly has drawbacks that make it insufficient. The biggest issue the author encountered reflected the criticisms made by Boers and Lindstromberg (2009) that unless it's selected by the teacher, input becomes too overwhelming for young learners. Furthermore, most young learners are unable to motivate themselves or are too immature to deal with the level of autonomy that Lewis' approach encourages. Nevertheless, there is a requirement for more focus towards lexis in the classroom. Lewis' ideas were highly radical when he first voiced them over twenty years ago; however, corpus studies have confirmed that chunks dominate everyday language. Additionally, cognitive linguists highlight how native children learners produce accurate chunks of language without having studied explicitly their grammatical makeup. Nevertheless, there is a need for more empirical evidence before many will be convinced to put their grammar textbook in the background.

\section{AUTHOR INFORMATION}

Mark Graham Sample is currently a lecturer at Hankuk University of Foreign Studies where he teaches Practical English courses to EFL students. He graduated from The University of Leeds and completed his Master of Arts in Applied Linguistics at The University of Nottingham. He has also taught at a public elementary school and at Chung-Ang University during the 6 years he has been living in South Korea. Email: sample5353@ gmail.com

\section{REFERENCES}

1. $\quad$ Alexander, L. (1967). First Things First. Longman.

2. Boers, F., \& Lindstromberg, S. (2009). Optimizing a Lexical Approach to Instructed Second Language Acquisition. Palgrave Macmillan: New York.

3. Feez, S. (1998). Text-Based Syllabus Design. Sydney: National Centre for English Teaching and Research.

4. $\quad$ Krashen, S. D. (1985). The input hypothesis. London: Longman.

5. Lewis, M. (1993). The Lexical Approach: The state of ELT and the way forward. Hove: Language Teaching Publications.

6. Lewis, M. (1996). 'Implications of a lexical view of language'. In Willis, J, and Willis, D. (eds.) Challenge and Change in Language Teaching, pp62-82. Longman. 
7. Lewis, M. (1997). Implementing the Lexical Approach: Putting Theory into Practice. Hove: Language Teaching Publications.

8. Lewis, M. (2000). Teaching collocation: further developments in the lexical approach. Hove: Language Teaching Publications.

9. $\quad$ Lindstromberg, S. (2000). My good-bye to the Lexical Approach. Copyright 2000 Pilgrims Ltd.

10. Lowe, C. (2003). Integration not eclecticism: a brief history of language teaching, 1853 - 2003. www.ihworld.com/ihjournal/charleslowe.asp

11. McCarthy, M. (2004). Using a Corpus in Language Teaching. CALPER Professional development Documents. http://calper.la.psu.edu/publications.php.

12. Moudraia, O. (2001). Lexical Approach to Second Language Teaching. http://www.cal.org/resources/digest/0102lexical.html

13. Richards, J. C., \& Rodgers, T. S. (2001). Approaches and Methods in Language Teaching. (2nd edition) Cambridge: Cambridge University Press.

14. Seog, M. Hendricks, K., \& Gonzalez-Moreno, P. A. (2011). Students' motivation to study music: The South Korean context. Research Studies in Music Education, 33(1), pp89-104.

15. Sohn, F. (2012). English 3. Cheonjae.

16. Sohn, F. (2012). English 4. Cheonjae.

17. Stern, H. H. (1983). Fundamental Concepts of Language Teaching. Oxford: Oxford University Press.

18. Thornbury, S. (1998). The Lexical Approach: a journey without maps? MET, 7(4), pp7-13.

19. White, R. V. (1998). The ELT Curriculum: Design, Innovation and Management. Oxford: Basil Blackwell.

20. Willis, J., \& Willis, D. (1989). Collins COBUILD English Course. London: Collins.

21. Wollam, J. (1992). Equality versus excellence - The South Korean dilemma in gifted education. Roeper Review, 14(4), pp212. 